\title{
Review \\ Year in review 2005: Critical Care - resource management
} André Carlos Kajdacsy-Balla Amaral ${ }^{1}$ and Gordon D Rubenfeld ${ }^{2}$

\author{
${ }^{1}$ Critical Care Department, Hospital São Lucas, Brasília, DF, Brazil \\ 2Pulmonary and Critical Care Medicine, Harborview Medical Center, University of Washington, Seattle, Washington, USA
}

Corresponding author: André Carlos Kajdacsy-Balla Amaral, decopastorius@yahoo.com.br

Published: 29 June 2006

This article is online at http://ccforum.com/content/10/3/215

(c) 2006 BioMed Central Ltd

Critical Care 2006, 10:215 (doi:10.1186/cc4953)

\begin{abstract}
During 2005 Critical Care published several original papers dealing with resource management. Emphasis was placed on sepsis, especially the coagulation cascade, prognosis and resuscitation. The papers highlighted important aspects of the pathophysiology of coagulation and inflammation in sepsis, as well as dealing with the proper use of newly developed compounds. Several aspects of prognosis in critically ill patients were investigated, focusing on biological markers and clinical indexes. Resuscitation received great attention, dealing with the effects of fluid infusion in hemodynamics and the lung. The information obtained can be used to address unknown effects of established therapies, to enlighten current clinical discussion on controversial topics, and to introduce novel medical resources and strategies. Future clinical work will rely heavily on these preclinical and laboratory data.
\end{abstract}

\section{Introduction}

During 2005 Critical Care published several original papers dealing with resource management. These papers focused mainly on sepsis and inflammation, with particular interest in the pathogenesis of the syndrome (especially the coagulation cascade and inflammatory aspects), analysis of prognostic indexes and markers, resuscitation and resource use in critical care.

\section{Coagulation in sepsis}

The importance of coagulation in sepsis has been the focus of attention by investigators for a few years [1]. Only recently has a compound, activated protein $\mathrm{C}(\mathrm{aPC})$, been shown effective and been approved for clinical use [2]. Because other natural anticoagulants have not been shown to be effective $[3,4]$, however, the question remains whether the anticoagulant characteristics of aPC are indeed responsible for the survival benefit, or whether certain anti-inflammatory or fibrinolytic properties may also come into play. This issue was investigated in a small case-control study that could demonstrate a decrease in thrombin generation, as reflected by decreased levels of thrombin-antithrombin and prothrombin fragments 1 and 2 after aPC administration [5]. The inflammatory mediators and parameters of fibrinolysis did not change, however, which suggests that the main action of aPC may be anticoagulation, not fibrinolysis or inhibition of inflammation. One must therefore argue not only about the importance of coagulation in sepsis, but also how it is inhibited, because the targets on the coagulation cascade of natural anticoagulants are different: tissue factor pathway inhibitor seems to be an 'all or none' mediator, specifically involved in initiating the coagulation cascade [6]. It would therefore probably be useful if it could be administered before coagulation was initiated.

Antithrombin III, on the other hand, works on later events in the cascade [7] and also benefits from specific interactions with endothelial glycosaminoglycans that may already be dysfunctional in sepsis [8]. Another report, however, showed that D-dimer levels in sepsis-acquired antithrombin III deficiency could be lowered by antithrombin III administration [9]. Interestingly, the effect was most pronounced in patients with very high D-dimer levels who where not using heparin, which could open space for new clinical trials in a specific septic population.

Finally, analysis from the original PROWESS data showed absolutely no difference in aPC benefit regardless of whether patients were treated with steroids [10]. This raises a point against the anti-inflammatory actions of aPC as its most important clinical effect, since low-dose steroids have also been shown to have anti-inflammatory effects [11,12], although their effects might be related to the correction of adrenal insufficiency [13] or to adrenoceptor modulation [14].

The safety of anticoagulants may be questioned in some clinical situations. The syndromes of purpura fulminas, meningococcal disease and meningitis, for example, are accompanied by severe coagulopathy and the risk for intracranial hemorrhage. Vincent and colleagues investigated this issue with data from four trials [15]. They could not show

$\mathrm{aPC}=$ activated protein $\mathrm{C} ; \mathrm{ICU}=$ intensive care unit; $\mathrm{IL}=$ interleukin. 
an increase in serious bleeding events for the overall population, but did notice an increased risk for developing intracranial hemorrhage in adult, but not pediatric, patients with meningitis when compared with all patients with sepsis treated with aPC. Unfortunately, this study primarily contained data on patients treated with this drug, so a direct comparison of risks (hemorrhage) and benefits (reduced mortality) cannot be inferred from these data.

\section{Prognosis in sepsis}

With the scarce intensive care unit (ICU) resources of the present day and the increasing costs of critical care, rationing beds and therapy has become an important issue in several countries. Adequate tools to predict clinical outcome are therefore mostly wanted. These tools would need to fulfill several criteria, such as precision, low cost and fast results. Furthermore, different scenarios could benefit from specific kinds of predictors. Triage in the emergency room for patients with community-acquired pneumonia, for example, would need a tool that could reliably distinguish three groups of patients: those patients that can be discharged home, those patients that need to be hospitalized, and those patients that need ICU care. This would need to be a one-point data collection, however, without sequential measurements. On the other hand, for septic patients already in the ICU, trends in specific markers may lead us to shorten or to prolong the duration of specific therapies (antibiotics, aPC), or to even withhold treatment for those that are unlikely to survive.

Unfortunately we are still far from adequate predictors. Outcome prediction models have been a focus for intensivists for over 30 years [16]. Various mathematical models have been used but the search for the 'best' model continues, although the exact use of empiric prognostic tools in the ICU has not been clarified. Current techniques, such as neural networks and classification trees, involve more sophisticated mathematical modeling as well as the addition of novel biomarkers to standard physiologic measures. Jaimes and colleagues compared neural networks and logistic models to predict mortality in patients with suspected sepsis in the Emergency Department [17]. Although there are some methodological issues in their model development, the use of neural networks seemed a better option. As with any new technology, however, caution must be taken when initially using these tools, and advice from experts should be sought.

Patients with postoperative hospital-acquired pneumonia who subsequently developed septic shock could be reasonably well separated from those patients who did not develop septic shock by elevated levels of immune modulating mediators (tumor necrosis factor alpha, IL-1 $\beta, \mathrm{IL}-6$, and E-selectin) [18]. Other clinical and laboratory markers were not helpful; specifically, C-reactive protein was not a good predictor of evolution to septic shock. Cytokine measurement at the bedside is unfortunately still expensive and is not fast enough to be clinically useful.
Christ-Crain and colleagues described a new marker in septic patients [19]. They measured mid-regional proadrenomedullin in 101 patients with inflammatory signs, and demonstrated increasing levels of proadrenomedullin with the progression from systemic inflammatory response syndrome to septic shock, and also greater levels in nonsurvivors. An important clinical question was not addressed, however: which severe sepsis/septic shock patient will survive or benefit from a specific therapy? A sequential evaluation of adhesion molecules in septic shock patients tried to focus on this issue [20], showing two clearly opposite patterns in the levels of markers that signal endothelial damage (soluble endothelial-linked adhesion molecule 1, soluble intercellular adhesion molecule 1). Survivors decreased their levels after 48 hours, while nonsurvivor levels continued to rise. This stresses two important points. First, serial changes in markers may be more useful than solitary baseline measures. Second, and the data are not yet nearly robust enough to allow this, sequential measures that predict a universally poor prognosis could be used to limit aggressive life-sustaining treatment. These decisions may be facilitated by biomarkers documenting a failure of a trial of intensive care.

The low availability of ICU beds and the increasing costs of critical care leave ICU managers with the tough decision of rationing. Specific diseases, especially those considered nontreatable, such as some forms of cancer and the acquired-immunodeficiency syndrome, are subjected to many forms of passive and silent rationing. Mrus and colleagues published interesting data showing that this may not be necessary in AIDS patients with severe sepsis and septic shock [21]. They not only confirmed that these patients are indeed less likely to be admitted to the ICU; they observed a similar length of stay and lower overall costs, but still a higher mortality. This may be in part due to previous expression of the patient's wish to withhold aggressive medical treatment (including ICU admission), possibly influenced by physician knowledge and laymen knowledge of the natural history of the disease, which is constantly changing. This is a decision that may therefore have to be re-evaluated due to current medical treatment and improved outcomes.

\section{Resuscitation}

Fluid resuscitation is still one of the more debatable topics in critical care. Even experienced physicians will not necessarily agree on resuscitation strategies. In the most extreme example, one might see some physicians administer fluids while other physicians facing the same clinical situation diurese. Despite clinical trial evidence informing practice, some clinicians find reasons to use colloids [22].

This uncertainty is understandable because we have very few large clinical studies on the fundamental topic of fluid resuscitation in critical care. Clinicians are left to guide their care based on their personal training and interpretation of 
physiologic principles. We must balance the alleged benefits of fluids (improved perfusion) with the potential harm (tissue edema).

The possible harm of increased lung edema was investigated by Martin and colleagues [23]. They observed that nonsurvivors of sepsis indeed had more extravascular lung water than survivors, and that extravascular lung water was associated with a worse oxygenation index. They could not, however, demonstrate any relationship between extravascular lung water and fluid balance. We are therefore forced to think that the individual inflammatory response is probably much more important than fluid balance in septic patients.

Experimental data from Dubin and colleagues in Argentina bring us interesting data regarding increasing oxygen delivery through fluid resuscitation in a septic model [24]. They clearly demonstrated that saline resuscitation, aimed at increasing the intestinal blood flow, led to lower mucosal ischemia as assessed by tonometry. This lower ischemia was accompanied by hyperchloremic acidosis, however, which may [25] or may not [26] be harmful.

The question therefore arises of which fluid to use? Analysis of the Sepsis Occurrence in Acutely ill Patients (SOAP) study brings more insight into this discussion, with special interest in albumin use [27]. Although a prospective study could not demonstrate any harm in critically ill patients from albumin resuscitation [28], Vincent and colleagues observed a $57 \%$ increase in mortality in patients receiving albumin matched with controls through a propensity score. Although this is an observational study, we are mostly inclined to avoid albumin use due to both lack of clinical benefit (and possibly harm) and also increased costs. Furthermore, we should ask ourselves what the clinical rationale is for colloid use in inflammatory conditions?

van Eijk and colleagues studied albumin extravasation in a sepsis model [29]. Although an increase in albumin extravasation could not be demonstrated in their endotoxemia model due to several methodological aspects, other papers have already described an increase of up to $300 \%$ in the loss of albumin to tissue spaces during septic shock [30], which is not corrected by albumin supplementation [31]. The question remains of whether albumin extravasation not only impairs its ability to maintain intravascular volume, but also whether the increase in interstitial osmotic pressure could be harmful due to cellular dehydration [32].

Another important issue is the question of goal-directed therapy. Pearse and colleagues demonstrated that central venous saturation and its trends can help discriminate patients who will develop complications after major surgery [33]. This study emphasizes the value of a simple and inexpensive monitoring tool and provides supportive data on the benefits of early resuscitation.
Two interesting studies on renal replacement therapy use surrogate endpoints of acidosis and hemodynamics; they therefore cannot guide therapy, but they can provide invaluable information about the pathophysiology and may inform future clinical trials. Both Page and colleagues [34] and Ratanarat and colleagues [35] studied the effects of renal replacement therapy in sepsis. Early hemodiafiltration, instituted if acidosis and oliguria persisted for 6-12 hours after resuscitation, was associated with better acidosis control, which was a marker of lower mortality [34]. Highvolume hemofiltration $(85 \mathrm{ml} / \mathrm{kg}$ ) led to better aerodynamics and to a lower than expected mortality ratio [35].

Improving the physiology does not always improve outcome. This is demonstrated by an observational study of abdominal decompression in patients with pancreatitis and elevated intra-abdominal pressure. There is a good rationale to operate on these patients, but De Waele and colleagues observed poor postoperative outcomes [36] and concluded that surgery would not be indicated to treat abdominal hypertension alone.

Finally, the importance of established and evidence-based protocols cannot be overemphasized. Noncompliance with modified 6-hour and 24-hour sepsis bundles was associated with a twofold increase in mortality [37]. The compliance rate was low, however, with only $52 \%$ compliance in the 6 -hour sepsis bundle and 30\% in the 24-hour bundle. Interestingly, the author's suggest the use of a process measure (compliance with the protocol) rather than the outcome for quality control in the ICU, which, although resource intensive, may bring earlier alarm signs and also an instrument for physician behavior modification.

\section{Miscellaneous}

Several important aspects of epidemiology, evaluation and treatment of the critically ill patient were observed in other Critical Care papers. Macias and colleagues asked whether the response to therapeutic interventions could be influenced by different levels of disease severity, including the suggestion that biological manipulation may be beneficial in the most severe patients and harmful in the less severe patients. They undertook a systematic review of published phase III sepsis trials and could not demonstrate this issue [38].

There has recently been a large interest in in vivo inspection of the microcirculation, which has been shown to be both deranged and associated with disease severity in sepsis [39]. However, the analysis of images derived from orthogonal polarized spectroscopy is still cumbersome and not customized. The comparison between studies is therefore challenging. Boerma and colleagues developed a semiquantitative method to evaluate the microcirculation and observed up to $90 \%$ agreement between observers [40]. Newer technology, in the form of sidestream dark-field, is already being introduced, however, which may allow more objective evaluations. 
Acidosis is a marker of disease severity in critical illness. Its understanding has recently been gaining more and more attention, based on Stewart's physicochemical approach [41]. The calculation of Stewart's parameters is cumbersome, however, and involves the collection of several nonroutine laboratory data. Simplification of the formulae to include only the effects of albumin and chloride was validated [42] and was shown to correlate well, explaining more than $80 \%$ of the unmeasured anions calculated with the complete approach.

Broessner and colleagues described a case of heat stroke managed with a novel intravascular cooling device [43]. We now know it is important to therapeutically cool patients after cardiac arrest and to therapeutically warm bleeding trauma patients $[44,45]$. However, in the most common scenario intensivists face, fever associated with systemic inflammatory response, we still do not know the optimal management [46]. A large body of animal data suggests that keeping a higher temperature may be beneficial, including the generation of heat-shock proteins [47], but many physicians usually treat fever - the main culprit is the increased oxygen consumption. As with many aspects of intensive care, the optimal physiologic target will depend on many factors.

In a similar direction (control of inflammation), anti-L-selectin antibodies were tested in a postseptic baboon model [48]. The authors carefully discuss the possible benefits of modulating the interaction of neutrophils with endothelial cells against the possibility of increased susceptibility to infections. L-Selectin was blocked before the onset of sepsis, and a lower bacterial load was observed in the treatment group. This intriguing finding must be demonstrated in other settings, but this could be a future approach to settings where inflammation is a key factor and infection comes into play later, such as trauma and extracorporeal circulation.

\section{Conclusion}

Last year's Critical Care papers brought to our attention various aspects of the pathophysiology, the diagnosis, the prognostication and the treatment of the critically ill patient. The information obtained can be used to address unknown effects of established therapies, to enlighten current clinical discussion on controversial topics, and to introduce novel medical resources and strategies. Future clinical work will rely heavily on these preclinical and laboratory data.

\section{Competing interests}

ACJ-BA received congress funding from Eli Lilly and Company.

\section{References}

1. Amaral A, Opal SM, Vincent JL: Coagulation in sepsis. Intensive Care Med 2004, 30:1032-1040.

2. Bernard GR, Vincent JL, Laterre PF, LaRosa SP, Dhainaut JF, Lopez-Rodriguez A, Steingrub JS, Garber GE, Helterbrand JD, Ely $\mathrm{EW}$, et al.: Efficacy and safety of recombinant human activated protein C for severe sepsis. N Engl J Med 2001, 344:699-709.

3. Warren BL, Eid A, Singer P, Pillay SS, Carl P, Novak I, Chalupa P, Atherstone A, Penzes I, Kubler A, et al.: Caring for the critically ill patient. High-dose antithrombin III in severe sepsis: a randomized controlled trial. JAMA 2001, 286:1869-1878.

4. Abraham E, Reinhart K, Opal S, Demeyer I, Doig C, Rodriguez AL, Beale R, Svoboda P, Laterre PF, Simon S, et al:: Efficacy and safety of tifacogin (recombinant tissue factor pathway inhibitor) in severe sepsis: a randomized controlled trial. JAMA 2003, 290:238-247.

5. de Pont AC, Bakhtiari K, Hutten BA, de Jonge E, Vroom MB, Meijers JC, Buller HR, Levi M: Recombinant human activated protein $\mathrm{C}$ resets thrombin generation in patients with severe sepsis - a case control study. Crit Care 2005, 9:R490-R497.

6. van 't Veer $C$, Mann KG: Regulation of tissue factor initiated thrombin generation by the stoichiometric inhibitors tissue factor pathway inhibitor, antithrombin-III, and heparin cofactor-II. J Biol Chem 1997, 272:4367-4377.

7. Blajchman MA, Austin RC, Fernandez-Rachubinski F, Sheffield WP: Molecular basis of inherited human antithrombin deficiency. Blood 1992, 80:2159-2171.

8. Klein NJ, Shennan Gl, Heyderman RS, Levin M: Alteration in glycosaminoglycan metabolism and surface charge on human umbilical vein endothelial cells induced by cytokines, endotoxin and neutrophils. J Cell Sci 1992, 102:821-832.

9. Kountchev J, Bijuklic K, Bellmann R, Wiedermann CJ, Joannidis M: Reduction of D-dimer levels after therapeutic administration of antithrombin in acquired antithrombin deficiency of severe sepsis. Crit Care 2005, 9:R596-R600.

10. Levy $H$, Laterre PF, Bates B, Qualy RL: Steroid use in PROWESS severe sepsis patients treated with drotrecogin alfa (activated). Crit Care 2005, 9:R502-R507.

11. Keh D, Boehnke $T$, Weber-Cartens S, Schulz C, Ahlers $O$, Bercker S, Volk HD, Doecke WD, Falke KJ, Gerlach H: Immunologic and hemodynamic effects of 'low-dose' hydrocortisone in septic shock: a double-blind, randomized, placebo-controlled, crossover study. Am J Respir Crit Care Med 2003, 167: 512-520.

12. Oppert MF, Schindler RF, Husung CF, Offermann KF, Graf KJ, Boenisch O, Boenisch OF, Barckow DF, Frei UF, Eckardt KU: Low-dose hydrocortisone improves shock reversal and reduces cytokine levels in early hyperdynamic septic shock. Crit Care Med 2005, 33:2457-2464.

13. Prigent $H$, Maxime V, Annane D: Clinical review: corticotherapy in sepsis. Crit Care 2004, 8:122-129.

14. Hoen S, Mazoit JX, Asehnoune K, Brailly-Tabard S, Benhamou D, Moine P, Edouard AR: Hydrocortisone increases the sensitivity to alpha1-adrenoceptor stimulation in humans following hemorrhagic shock. Crit Care Med 2005, 33:2737-2743.

15. Vincent JL, Nadel S, Kutsogiannis DJ, Gibney RT, Yan SB, Wyss VL, Bailey JE, Mitchell CL, Sarwat S, Shinall SM, et al:: Drotrecogin alfa (activated) in patients with severe sepsis presenting with purpura fulminans, meningitis, or meningococcal disease: a retrospective analysis of patients enrolled in recent clinical studies. Crit Care 2005, 9:R331-R343.

16. Afifi AA, Sacks ST, Liu VY, Weil MH, Shubin H: Accumulative prognostic index for patients with barbiturate, glutethimide and meprobamate intoxication. N Engl J Med 1971, 285:14971502.

17. Jaimes F, Farbiarz J, Alvarez D, Martinez C: Comparison between logistic regression and neural networks to predict death in patients with suspected sepsis in the emergency room. Crit Care 2005, 9:R150-R156.

18. von Dossow V, Rotard K, Redlich U, Hein OV, Spies CD: Circulating immune parameters predicting the progression from hospital-acquired pneumonia to septic shock in surgical patients. Crit Care 2005, 9:R662-R669.

19. Christ-Crain $M$, Morgenthaler NG, Struck J, Harbarth $S$, Bergmann A, Muller B: Mid-regional pro-adrenomedullin as a prognostic marker in sepsis: an observational study. Crit Care 2005, 9:R816-R824.

20. Hein OV, Misterek K, Tessmann JP, van Dossow V, Krimphove M, Spies C: Time course of endothelial damage in septic shock: prediction of outcome. Crit Care 2005, 9:R323-R330.

21. Mrus JM, Braun L, Yi MS, Linde-Zwirble WT, Johnston JA: Impact of HIV/AIDS on care and outcomes of severe sepsis. Crit Care 2005, 9:R623-R630.

22. Fodor L, Fodor A, Ramon Y, Shoshani O, Rissin Y, Ullmann Y: Controversies in fluid resuscitation for burn management: literature review and our experience. Injury 2006, 37:374-379. 
23. Martin GS, Eaton S, Mealer M, Moss M: Extravascular lung water in patients with severe sepsis: a prospective cohort study. Crit Care 2005, 9:R74-R82.

24. Dubin A, Murias G, Maskin B, Pozo MO, Sottile JP, Baran M, Edul VS, Canales HS, Badie JC, Etcheverry G, et al.: Increased blood flow prevents intramucosal acidosis in sheep endotoxemia: a controlled study. Crit Care 2005, 9:R66-R73.

25. Kellum JA, Song M, Venkataraman R: Effects of hyperchloremic acidosis on arterial pressure and circulating inflammatory molecules in experimental sepsis. Chest 2004, 125:243-248.

26. Qian $T$, Nieminen AL, Herman B, Lemasters JJ: Mitochondrial permeability transition in $\mathrm{pH}$-dependent reperfusion injury to rat hepatocytes. Am J Physiol Cell Physiol 1997, 273:C1783C1792.

27. Vincent JL, Sakr Y, Reinhart K, Sprung CL, Gerlach H, Ranieri VM: Is albumin administration in the acutely ill associated with increased mortality? Results of the SOAP study. Crit Care 2005, 9:R745-R754.

28. Finfer S, Bellomo R, Boyce N, French J, Myburgh J, Norton R; SAFE Study Investigators: A comparison of albumin and saline for fluid resuscitation in the intensive care unit. $N$ Engl J Med 2004, 350:2247-2256.

29. van Eijk LT, Pickkers $P$, Smits $P$, van den BW, Bouw MP, van der Hoeven JG: Microvascular permeability during experimental human endotoxemia: an open intervention study. Crit Care 2005, 9:R157-R164

30. Fleck A, Raines G, Hawker F, Trotter J, Wallace PI, Ledingham IM, Calman KC: Increased vascular permeability: a major cause of hypoalbuminaemia in disease and injury. Lancet 1985, 1:781784.

31. Margarson MP, Soni NC: Effects of albumin supplementation on microvascular permeability in septic patients. J Appl Physio/ 2002, 92:2139-2145.

32. Ernest D, Belzberg AS, Dodek PM: Distribution of normal saline and $5 \%$ albumin infusions in septic patients. Crit Care Med 1999, 27:46-50.

33. Pearse R, Dawson D, Fawcett J, Rhodes A, Grounds RM, Bennett ED: Changes in central venous saturation after major surgery, and association with outcome. Crit Care 2005, 9:R694-R699.

34. Page B, Vieillard-Baron A, Chergui K, Peyrouset O, Rabiller A, Beauchet $A$, Aegerter $P$, Jardin F: Early veno-venous haemodiafiltration for sepsis-related multiple organ failure. Crit Care 2005, 9:R755-R763.

35. Ratanarat $R$, Brendolan A, Piccinni P, Dan M, Salvatori G, Ricci Z, Ronco C: Pulse high-volume haemofiltration for treatment of severe sepsis: effects on hemodynamics and survival. Crit Care 2005, 9:R294-R302.

36. De Waele JJ, Hoste E, Blot SI, Decruyenaere J, Colardyn F: Intraabdominal hypertension in patients with severe acute pancreatitis. Crit Care 2005, 9:R452-R457.

37. Gao F, Melody T, Daniels DF, Giles S, Fox S: The impact of compliance with 6-hour and 24-hour sepsis bundles on hospital mortality in patients with severe sepsis: a prospective observational study. Crit Care 2005, 9:R764-R770.

38. Macias WL, Nelson DR, Williams M, Garg R, Janes J, Sashegyi A: Lack of evidence for qualitative treatment by disease severity interactions in clinical studies of severe sepsis. Crit Care 2005, 9:R607-R622.

39. Sakr Y, Dubois MJ, De Backer D, Creteur J, Vincent JL: Persistent microcirculatory alterations are associated with organ failure and death in patients with septic shock. Crit Care Med 2004, 32:1825-1831.

40. Boerma EC, Mathura KR, van der Voort PH, Spronk PE, Ince C: Quantifying bedside-derived imaging of microcirculatory abnormalities in septic patients: a prospective validation study. Crit Care 2005, 9:R601-R606.

41. Stewart PA: Modern quantitative acid-base chemistry. Can J Physiol Pharmacol 1983, 61:1444-1461.

42. O'Dell E, Tibby SM, Durward A, Aspell J, Murdoch IA: Validation of a method to partition the base deficit in meningococcal sepsis: a retrospective study. Crit Care 2005, 9:R464-R470.

43. Broessner G, Beer R, Franz G, Lackner P, Engelhardt K, Brenneis C, Pfausler B, Schmutzhard E: Case report: severe heat stroke with multiple organ dysfunction - a novel intravascular treatment approach. Crit Care 2005, 9:R498-R501.

44. Bernard SA, Gray TW, Buist MD, Jones BM, Silvester W, Gutteridge G, Smith K: Treatment of comatose survivors of out-of- hospital cardiac arrest with induced hypothermia. $N$ Engl J Med 2002, 346:557-563.

45. Gentilello LM, Jurkovich GJ, Stark MS, Hassantash SA, O'Keefe GE: Is hypothermia in the victim of major trauma protective or harmful? A randomized, prospective study. Ann Surg 1997, 226:439-447.

46. Ryan M, Levy MM: Clinical review: fever in intensive care unit patients. Crit Care 2003, 7:221-225.

47. Su F, Nguyen ND, Wang Z, Cai Y, Rogiers P, Vincent JL: Fever control in septic shock: beneficial or harmful? Shock 2005, 23:516-520.

48. Redl HR, Martin U, Khadem A, Pelinka LE, van Griensven M: AntiL-selectin antibody therapy does not worsen the postseptic course in a baboon model. Crit Care 2005, 9:R735-R744. 